statistical) approach of quantitative genetics (for example, Falconer, 1960). The concept of heritability is not introduced until page 195. Unfortunately, the opportunity is missed to match the notation of the 2 approaches and show where they overlap.

Because so much of the material and methodology deals with pure breeding or inbred lines of plants and their crosses, the book will probably be of little interest to medical geneticists dealing with family pedigree data or data from different kinds of relatives. Its main asset will be that it can give a quick and simple insight into these alternative methods of genetic analysis of continuous traits.

C. SMITH

\section{Guidelines for Research Involving Recombinant DNA Molecules}

(Pp. vi +181 ; Figures + Tables.) US Department of Health, Education, and Welfare. 1976.

The research covered by these guidelines has provoked unprecedented public interest, and has already produced fascinating results in genetics. There is no doubt that the results are so exciting that work in this field will expand greatly and continue to be important for many years.

The guidelines cover experiments in which different segments of DNA (for example, a mammalian structural gene and a bacterial plasmid) are joined together by chemical methods and then have the ability to infect and replicate in some host cell (for example, Esch. coli). In this way large amounts of 'cloned' DNA can be prepared quickly and cheaply. There is also the possibility that in some cases the bacteria could produce the protein product of a mammalian gene (for example, a peptide hormone). Fears have been raised that either all or some of the experiments which could be carried out present a potential biohazard. This feeling has been increased by the indiscriminate use of the evocative term 'genetic engineering' to cover all such experiments. The National Institute of Health has tried to assess the potential hazard of a variety of manipulations, and the guidelines present detailed experimental procedures to deal with most situations, at least in laboratories dependent on NIH funding. The position is unusual in that, despite much guessing and speculating on the hazards, very few experimental data are available.

The guidelines categorise experiments according to the source and purity of DNA and the disablement, or inability to live outside an experimental environment, of the bacteria used for growth. They then specify a level of containment to match the estimated potential hazard. They recognise both physical (P numbers) and biological (EK numbers) containment and express their hope that better forms of biological containment will be developed.

Physical containment varies from minimal, where the main protection is use of good microbiological practices, to high, a specially constructed laboratory designed to contain micro-organisms that may cause serious epidemic disease.

However, in addition to defining all levels of containment, the NIH guidelines state that certain experiments may not be initiated at the present time. These include cloning of DNA from oncogenic viruses or the deliberate formation of recombinant DNAs containing genes for the biosynthesis of potent toxins (for example, diphtheria toxins or snake venoms).

An interesting section of the guidelines deals with 'Roles and responsibilities'. Much responsibility devolves onto the principal investigator and the institutional biohazard committee. As well as having technical expertise, the biohazard committee must be able to assess the acceptability of its decisions to the local community and its Minutes must be available for public inspection.

Extensive appendices provide supplementary information on physical containment and discussion of alternative vectors.

The details of the guidelines are constantly being brought up to date and the researcher involved in this field needs to be ever alert. Evidence of this may be seen in the criticism of the Californian workers who cloned the rat insulin gene (see Science, September 30). British research workers use a different set of guidelines (set out in the Williams report, HMSO), which are roughly comparable and which are administered by a Genetic Manipulation Advisory Group. Most other countries are using one or other of these sets of guidelines.

S. MALCOLM

Gene-Environment Interaction in Common Diseases. Proceedings of the Symposium on Gene-Environment Interaction in Common Diseases held February 11-12, 1976, Tokyo.

Edited by Eiji Inouye and Hideo Nishimura. (Pp. 234; Figures + Tables. £21·25.) Baltimore, London, and Tokyo: University Park Press. 1977.

The publication of a volume from Japan on this important topic raised hopes in the reviewer that this book might prove to be a valuable source of original experimental data and ideas from Japan in the field of genetics and epidemiology. Not only has one had the suspicion that much important Japanese work is neglected or entirely ignored in the Western literature, 
but data from Japan should provide insight into some of the specific environmental and genetic factors involved in the commoner malformations and chronic diseases.

Unfortunately, this book fulfils these hopes only to a limited extent. It is the published version of a symposium and lacks the cohesion of a monograph or deliberate review. In addition, prominence is given to the contributions of a number of invited European and American speakers, which for the most part cover familiar ground and provide little new information that justifies their publication here. An exception should be made of the forceful contribution by Newton Morton on genetic epidemiology, which provides a valuable theoretical basis and a corrective to the view that empirical risks are all that matter in multifactorial inheritance. The Japanese contributions, by contrast, have frequently been condensed into brief summaries, in which the conclusions cannot be backed up by details of ascertainment and analysis.

Despite these limitations, there are some valuable reports. A discussion by Yasuda of the embryogenesis of human limb malformations, based on the abundance of human fetal material, shows that the different types of polydactyly can be recognised at a stage well before development of the actual digits. It is a pity that no data on neural tube defects based on this material were presented. An extensive study of congenital heart disease by Ando et al. indicates clear differences in the frequency of the individual types of defect in Japan, as compared with Europe and America, together with some surprising deviations in the risks to sibs from those expected on grounds of multifactorial inheritance. This again might lead one to suppose different environmental factors to be involved, but the adequacy of methods of collecting genetic data has to be questioned, since in this paper no mention is made of how the information was collected, while a similar study of cleft palate relied on questionnaires. In both studies, a recurrence risk lower than expected was found, and one suspects that inadequate design of study may have been responsible.

In addition to the epidemiological surveys, the book contains a number of contributions on theoretical population genetics, notably a paper by Maruyama on genetic load, as well as some interesting experimental animal studies on central nervous system malformations and hypertensive cerebral disease. The impression left by the book as a whole is that the Japanese contributions to theoretical genetics and experimental pathology have not yet been fully applied to the field of clinical genetics, neither has the full potential of Japan for epidemiological and genetic studies yet been recognised.

Finally one has to ask why the publishers have priced this book of 234 pages at $£ 21.25$ ? It is to be hoped that this deterrent from purchasing the book does not prevent medical geneticists in Europe and America from reading at least some of the more interesting chapters.

Peter S. Harper

Medical Genetics. Proceedings of the Symposium at Debrecen-Hajdúszoboszló, Hungary, 27-29 April, 1976.

Edited by G. Szabó and Z. Papp. (Pp. 911; Figures + Tables. US \$1 14.35, Df 280.) Amsterdam and Oxford: Excerpta Medica. 1977.

This splendidly produced volume of the Proceedings of the Symposium on Medical Genetics, held at Debrecen-Hajdúszoboszló, Hungary, in April 1976, which well over 200 geneticists from all over the world attended, contains some 112 papers grouped into 5 subjects. The section on chromosome mapping and clinical cytogenetics contains a valuable review of some of the current research in Down's syndrome, some valuable papers on sex chromosome abnormalities and sex determination, and one or two hitherto poorly described syndromes associated with aneuploidy or structural rearrangements, among many other aspects of cytogenetic research. The papers dealing with population genetics and congenital malformations are varied and interesting, especially one on 'Relation between population genetics and population teratology', and some on the genetic aspects of psychiatric problems. Prenatal diagnosis is well covered with reports from Switzerland, Hungary, Holland, and Belgium. A number of papers are devoted to biochemical aspects of amniotic fluid, and several papers deal with various facets of genetic counselling, including one on the relation between epidemiology and genetic counselling, and another dealing specifically with the problems posed by adoption. The final section contains a number of interesting and valuable papers on the haemoglobinopathies, including one from Hungary appropriately on haemoglobin J-Buda and G-Pest tests.

This is an unusually well-produced Proceedings issue containing many papers from Eastern European countries, but especially from Hungary. The editors must be congratulated.

K. M. Laurence

Clinics in Rheumatic Diseases, Vol. 3, No. 2. Immunogenetics and Rheumatic Disease

Edited by Derrick Brewerton. (Pp. vii +309 ; Figures

+ Tables. £8.25.) London, Philadelphia, and Toronto:

Saunders. 1977.

The major advances in clinical genetics in recent decades have largely concerned traits and diseases 